\title{
Hydroxyalkylation of Cyclic Imides with Oxiranes Part III. Mechanism of the Reaction in Presence of Sodium Hydroxide Catalyst
}

\author{
Jacek Lubczak, Renata Lubczak, Dorota Naróg \\ Faculty of Chemistry, University of Technology, Rzeszów, Poland \\ Email: jml@prz.edu.pl
}

How to cite this paper: Lubczak, J., Lubczak, R. and Naróg, D. (2018) Hydroxyalkylation of Cyclic Imides with Oxiranes Part III. Mechanism of the Reaction in Presence of Sodium Hydroxide Catalyst. Open Journal of Physical Chemistry, 8, 67-79.

https://doi.org/10.4236/ojpc.2018.83005

Received: August 10, 2018

Accepted: August 27, 2018

Published: August 30, 2018

Copyright $\odot 2018$ by authors and Scientific Research Publishing Inc. This work is licensed under the Creative Commons Attribution International License (CC BY 4.0).

http://creativecommons.org/licenses/by/4.0/

\begin{abstract}
The kinetics of reaction between cyclic monoimides (succinimide, phtalimide, and glutarimide) with ethylene and propylene oxides in presence of sodium hydroxide was studied. The effect of substrate and catalyst concentrations on the course of the reaction was investigated. Kinetics of reaction was studied by dilatometry, i.e. by measuring volume contraction of reaction mixture. The kinetic law describing the reaction of imides with oxiranes is: $V=k c_{c a t}^{1 / 2} c_{A H}^{1 / 2} c_{B}$. where $c_{c a p} c_{A H}$ and $c_{B}$ are concentrations of catalyst, imide, and oxirane, respectively. The relative reactivity of imides and oxiranes was: GI $>\mathrm{PI} \geq \mathrm{SI}$ and EO $>$ PO. The reaction mechanism was proposed based upon experimentally determined rate law for the reaction of cyclic monoimides and oxiranes as well as analytical and instrumental analysis of products. The elementary reaction between oxirane and imide anion is rate determining step. The imide anion is formed by hydrogen cation transfer into catalytic hydroxide anion from dissociated $\mathrm{NaOH}$. In the consecutive elemental reaction an imidate anion attack on the oxirane molecule occurs. It is the slowest stage of the reaction, limiting the entire process. All the studied reactions obey the same mechanism as can be concluded from isokinetic relationship of studied systems)
\end{abstract}

\section{Keywords}

Imides, Oxiranes, Catalyst, Kinetic, Reactivity of Reagents, Thermodynamic Parameters, Mechanism of Reaction

\section{Introduction}

Cyclic imides (I) like succinimide (SI, $\left.\mathrm{R}=\left(-\mathrm{CH}_{2}-\right)_{2}\right)$, glutarimide (GI, $\mathrm{R}=$ 
$\left.\left(-\mathrm{CH}_{2}-\right)_{3}\right)$, or phtalimide $(\mathrm{PI}, \mathrm{R}=\mathrm{Ph}$ ) have characteristic $\mathrm{O}=\mathrm{C}-\mathrm{NH}-\mathrm{C}=\mathrm{O}$ group in which hydrogen is weakly acidic. Due to weakly acidic hydrogen they are able to react with oxiranes like ethylene oxide (EO) or propylene oxide (PO) to give $\mathrm{N}$-(hydroxyalkyl)imides (II) according to the scheme below:<smiles>[R]1CONO1</smiles>

(I)

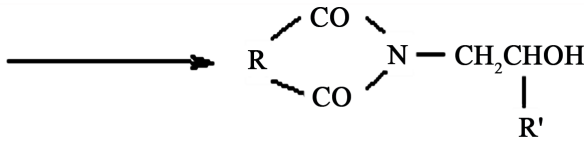

(II)

where:

$$
\mathrm{R}^{\prime}=-\mathrm{H},-\mathrm{CH}_{3}
$$

Hydroxyalkylation of cyclic monoimides has been exploited mostly for syntheses [1] [2] [3] [4]. Knowledge on the kinetics and mechanism of the reaction is limited to two publications [5] [6]. On the other hand the kinetics and mechanism of reaction of oxiranes with compounds containing acidic groups like alcohols, thiols, carboxylic acids, amides are well recognized [2] [7]-[13]. Reaction analysis of cyclic monoimides with oxiranes is important because oligoeterols obtained by hydroxylation of multifunctional cyclic imides like isocyanuric, uric, parabanic and barbituric acid are useful substrates to obtain polymers of good thermal resistance, especially widely used polyurethane foams (PUFs) [14]. Encountered multifunctional cyclic imides are not suitable for monitoring the kinetics of reaction with oxiranes due to their low solubility in contrary to cyclic monoimides [5] [6]. The kinetics and mechanism of reaction between oxiranes (EO and PO) with SI, PI, and GI in presence of triethylamine (TEA) was studied in details and general rate low was found as [5]:

$$
V=k_{1 / 2}^{\prime \prime} c_{\mathrm{k}}^{1 / 2} c_{\mathrm{AH}}^{3 / 2} c_{\mathrm{B}}^{1 / 2}
$$

where $c_{\mathrm{k}}, c_{\mathrm{AH}}$ and $c_{\mathrm{B}}$ are concentrations of catalyst, imide, and oxirane, respectively.

It has been found that the reactions have consecutive-parallel character. The obtained product: $\mathrm{N}$-(hydroxyalkyl)imide (II) is further engaged in oxirane. This leads to presence of consecutive reaction product with $5-10$ mol\%. Based on determined rate constants the reactivity of imides and oxiranes can be put in the following rows: $\mathrm{PI} \geq \mathrm{SI}>\mathrm{GI}$ and $\mathrm{EO}>\mathrm{PO}$, respectively. The values of the Gibbs activation energy were determined in function of temperature and the possible mechanism of reaction was proposed. It has been concluded the consecutive reactions i.e. the reaction of $\mathrm{N}$-(hydroxyalkyl)imides with oxiranes follow different mechanism than reaction of imide with oxirane. The oxirane-related order of consecutive reaction is 1 in comparison with $1 / 2$ for reaction of imide with oxirane [5] [6]. In order to further understand the mechanism of these processes we have undertaken detailed study on kinetics of reaction between cyclic imides and oxiranes in presence of sodium hydroxide catalyst. 


\section{Experimental}

\subsection{Starting Materials}

SI, PI, GI (pure, Sigma-Aldrich) were recrystallized from ethanol (reagent grade, POCH, Poland). Dimethylsulfoxide (DMSO, pure, Avocado, Germany) was dried over molecular sieves $4 \mathrm{~A}$ (POCH, Poland), while EO and PO (racemate) (pure, Fluka, Switzerland) and sodium hydroxide (reagent grade, $\mathrm{POCH}$, Poland) were used as received.

\subsection{Kinetic Measurements}

Weighed sample of imide was placed in $50 \mathrm{~cm}^{3}$ volumetric flask and dissolved in ca $30 \mathrm{~cm}^{3}$ DMSO. After dissolving of imide and $\mathrm{NaOH}$ as catalyst the temperature of the solution was raised to $25^{\circ} \mathrm{C}, 30^{\circ} \mathrm{C}, 35^{\circ} \mathrm{C}, 40^{\circ} \mathrm{C}, 45^{\circ} \mathrm{C}$ or $50^{\circ} \mathrm{C}$ $\left( \pm 0.05^{\circ} \mathrm{C}\right)$. Oxiranes (EO or $\left.\mathrm{PO}\right)$ as liquids stored in refrigerator were transferred into the flask, the volume was adjusted with DMSO and then the flask was immediately closed to avoid evaporation of boiling oxirane and weighed. The concentration of oxirane was calculated based on mass of substrates used. The solutions prepared in that way were then rapidly transferred into thermostated dilatometer.

The influence of catalyst concentration on the rate of reaction was studied at constant concentration of imide and EO $\left(1.0 \mathrm{~mol} / \mathrm{dm}^{3}\right)$. The sodium hydroxide concentration was varied within $0.05 \div 0.20 \mathrm{~mol} / \mathrm{dm}^{3}$ region with $0.05 \mathrm{~mol} / \mathrm{dm}^{3}$ step. The influence of imide concentration on the rate of reaction was studied at constant concentration of EO $\left(0.25 \mathrm{~mol} / \mathrm{dm}^{3}\right)$ and catalyst $\left(0.20 \mathrm{~mol} / \mathrm{dm}^{3}\right)$ with variable imide concentration within $2 \div 4 \mathrm{~mol} / \mathrm{dm}^{3}$ region.

The temperature dependence was obtained for the system with $1.0 \mathrm{~mol} / \mathrm{dm}^{3}$ imide and oxirane and $0.20 \mathrm{~mol} / \mathrm{dm}^{3} \mathrm{NaOH}$ concentrations within $25^{\circ} \mathrm{C} \div 40^{\circ} \mathrm{C}$ for the reaction with $\mathrm{EO}$ and $35^{\circ} \mathrm{C} \div 50^{\circ} \mathrm{C}$ for the reaction with $\mathrm{PO}$ with $5^{\circ} \mathrm{C}$ intervals. The temperature range for kinetic measurements is limited from lower side by long reaction time ( 2 weeks for EO to 1.5 months for PO), which precludes the good accuracy of measurement, and from the higher side by boiling of oxiranes in reaction mixture (above $40^{\circ} \mathrm{C}$ for $\mathrm{EO}$ and $50^{\circ} \mathrm{C}$ for PO).

Kinetics of reaction was studied by dilatometry, i.e. by measuring volume contraction of reaction mixture, as it was described before [5]. Relative concentration of oxirane $(b)$ was defined as

$$
b=\frac{c_{\mathrm{B}}}{c_{0 \mathrm{~B}}}
$$

where: $c_{0 \mathrm{~B}}, c_{\mathrm{B}}$-corresponding to initial and instantaneous concentrations of oxirane, $\mathrm{mol} / \mathrm{dm}^{3}$.

In order to establish the rate low, the substitution method was applied. The values of relative concentration of oxirane, $c_{\mathrm{B}}$ obtained for $0.2-0.8$ region with 0.05 step and reaction time were put into the kinetic law equations of various orders. Considering the system with EO as standard, the relative reactivity of PO $\left(r_{\mathrm{PO}}\right)$ was used as the ratio of the rate constants at the same temperature: 


$$
r_{\mathrm{PO}}=\frac{k_{\mathrm{PO}}}{k_{\mathrm{EO}}}
$$

where: $k_{\mathrm{PO}}, k_{\mathrm{EO}}$-rate constants for $\mathrm{PO}$ and $\mathrm{EO}$, respectively.

Relative reactivity of imides was analyzed in analogous manner using succinimide as standard.

The activation energy $\left(\Delta G^{ \pm}\right)$was calculated from [15]:

$$
\Delta G^{\neq}=R T \cdot\left(23764-\ln \frac{k}{T}\right)
$$

where: $R$-gas constant $[\mathrm{J} / \mathrm{mol} \cdot \mathrm{K}]$,

$T$-temperature of measurement, [K],

$k$-rate constant.

By plotting $\Delta G^{\star}$ versus $T$ a straight line was obtained with activation enthalpy $\left(\Delta H^{\ddagger}\right)$ and entropy $\left(\Delta S^{\star}\right)$ of the reaction as the coefficients of the line [15]:

$$
\Delta G^{\neq}=\Delta H^{\neq}-T \cdot \Delta S^{\neq}
$$

\subsection{Product Analysis}

The products of reactions were isolated after full kinetic run. The DMSO was distilled off under reduced pressure and $\mathrm{N}$-(hydroxyalkyl)imides were isolated as solids, which were recrystallized from ethanol or benzene. Pure products were characterized by melting point, and by the IR spectra (ALPHA FT-IR BRUKER spectrometer). The yield was estimated based on chromatographic analysis (LC chromatograph KB 5901, prod. COBRABID, Poland), as described in [5].

\subsection{Conductometric Measurements}

Conductometric measurements were performed for solutions of imides, sodium hydroxide and mixture of them in DMSO in thermostated $20 \mathrm{~cm}^{3}$ cell at $20^{\circ} \mathrm{C}$ $( \pm 0.1)$.

\section{Results and Discussion}

\subsection{Kinetics}

The rate law for the reaction of SI with EO was obtained by substituting the instantaneous values of relative oxirane concentration, $b$ (Equation (3)) and reaction time into kinetic equations of various orders (Table 1 ). It has been found that reaction of SI with EO obey 3/2 order rate low (Table 1 ).

$$
V=-\frac{\mathrm{d} c_{\mathrm{B}}}{\mathrm{d} t}=k_{3 / 2} c^{3 / 2}
$$

The reaction depends on catalyst concentration. The relationship between rate constant derived from Equation (7) and catalyst concentration was:

$$
k_{3 / 2}=k_{3 / 2}^{\prime} c_{\text {cat }}^{n}
$$

When plotting $\lg k_{3 / 2}=f\left(g \mathcal{c}_{\mathrm{cat}}\right)$ the $n \approx 0.5$ was obtained (Figure 1 ). In order to determine power coefficient for oxirane concentration and imide concentration 


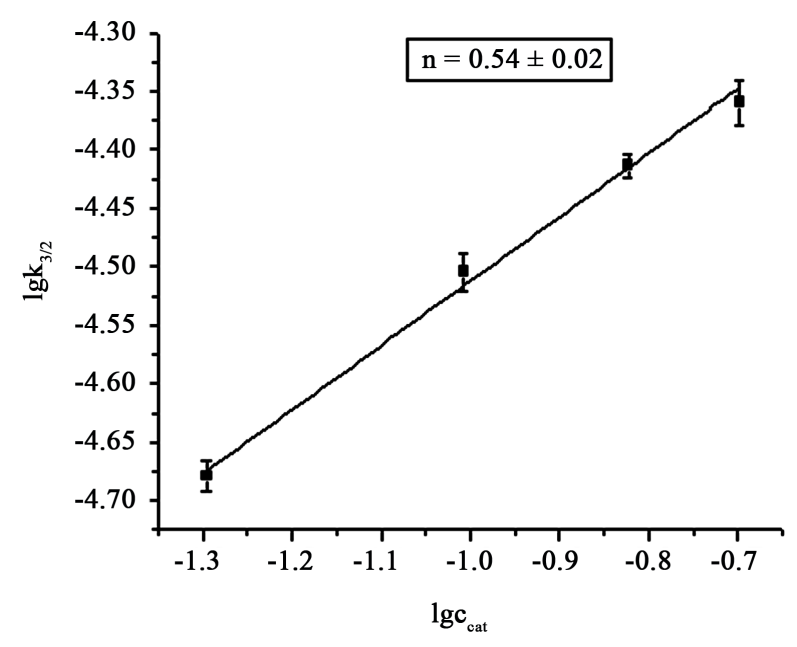

Figure 1. The plot of rate constant versus catalyst concentration for the reaction of SI with EO.

Table 1. Rate constants for the reaction of PI with $\mathrm{EO}$ at $298 \mathrm{~K}\left(25^{\circ} \mathrm{C}\right)$ calculated for various kinetic laws.

\begin{tabular}{ccccc}
\hline \multicolumn{5}{c}{$c_{0} \mathrm{PI}=0.9998 \mathrm{~mol} / \mathrm{dm}^{3}, c_{0} \mathrm{EO}=0.9993 \mathrm{~mol} / \mathrm{dm}^{3}, c_{\mathrm{NaOH}}=0.2064 \mathrm{~mol} / \mathrm{dm}^{3}$} \\
\hline $\begin{array}{c}\text { Reaction time } \\
{[\mathrm{min}]}\end{array}$ & $\begin{array}{c}\text { Relative concentration } \\
\text { of EO }(\mathrm{b})\end{array}$ & $\begin{array}{c}k_{1} \cdot 10^{5} \\
{\left[\mathrm{~s}^{-1}\right]}\end{array}$ & $\begin{array}{c}k_{3 / 2} \cdot 10^{5} \\
{\left[\mathrm{~mol}^{-1 / 2} \cdot \mathrm{s}^{-1} \cdot \mathrm{dm}^{3 / 2}\right]}\end{array}$ & $\begin{array}{c}k_{2} \\
{\left[\mathrm{~mol}^{-1} \cdot \mathrm{s}^{-1} \cdot \mathrm{dm}^{3}\right]}\end{array}$ \\
\hline 320 & 0.8057 & 1.13 & 1.19 & 1.26 \\
450 & 0.7416 & 1.11 & 1.19 & 1.29 \\
540 & 0.6954 & 1.12 & 1.23 & 1.35 \\
650 & 0.6543 & 1.09 & 1.21 & 1.35 \\
720 & 0.6239 & 1.09 & 1.23 & 1.40 \\
920 & 0.5672 & 1.03 & 1.19 & 1.38 \\
1080 & 0.5084 & 1.04 & 1.24 & 1.49 \\
1260 & 0.4664 & 1.01 & 1.23 & 1.51 \\
1380 & 0.4369 & 1.00 & 1.24 & 1.56 \\
1880 & 0.3581 & 1.00 & 1.19 & 1.59 \\
2220 & 0.3035 & 0.95 & 1.22 & 1.72 \\
2550 & 0.2689 & 0.85 & 1.21 & 1.78 \\
3220 & 0.2185 & 0.79 & 1.18 & 1.85 \\
$k_{3 / 2}$ av $10^{5}\left[\mathrm{~mol}^{-1 / 2} \cdot \mathrm{s}^{-1} \cdot \mathrm{dm}^{3 / 2}\right]$ & & $1.21 \pm 0.02$ & \\
\hline & & & & \\
\hline & & & & \\
\hline
\end{tabular}

the kinetics was followed at high excess of imide ( 8 - 16-fold) in relation to oxirane to keep $c_{\mathrm{AH}} \gg c_{\mathrm{B}}$. Thus $c_{\mathrm{AH}}=$ const. was assumed. Then the order of reaction for oxirane was 1 (Table 2). This results in the following equation:

$$
k_{1}=k_{1}^{\prime} c_{\mathrm{AH}}^{p}
$$

According to kinetic data kinetic order for imide groups was $p \approx 0.5$ (Figure 2). Thus the kinetic law describing the reaction of SI with EO is: 


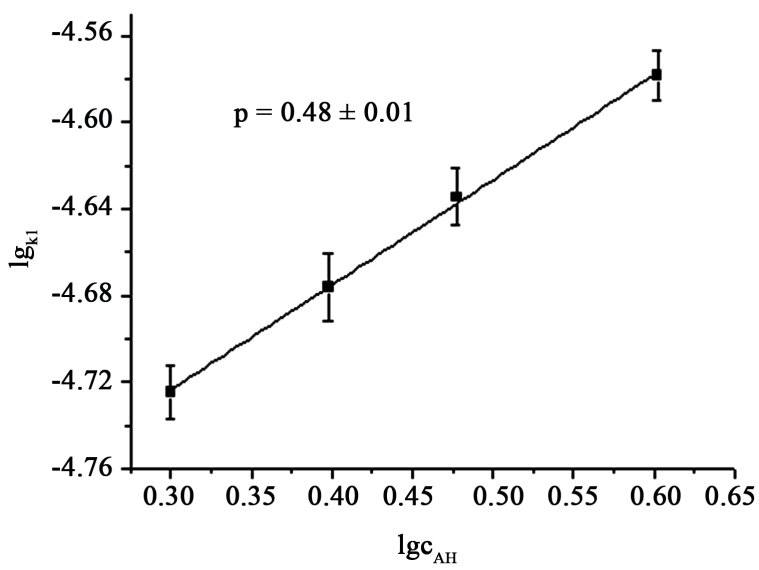

Figure 2. The plot of rate constant versus imide concentration for the reaction of SI with EO.

Table 2. Rate constants for the reaction of SI with $\mathrm{EO}$ at $313 \mathrm{~K}\left(40^{\circ} \mathrm{C}\right)$ calculated for first order kinetic equation for oxirane.

\begin{tabular}{ccc}
\hline$c_{0} \mathrm{SI}=4.0012 \mathrm{~mol} / \mathrm{dm}^{3}$ & $c_{0} \mathrm{EO}=0.2508=\mathrm{mol} / \mathrm{dm}^{3}$ & $\mathcal{c}_{\mathrm{NaOH}}=0.2014 \mathrm{~mol} / \mathrm{dm}^{3}$ \\
\hline Reaction time $[\mathrm{min}]$ & Relative concentration of $\mathrm{EO}(\mathrm{b})$ & $k_{1} \cdot 10^{5}\left[\mathrm{~s}^{-1}\right]$ \\
\hline 130 & 0.8075 & 2.74 \\
180 & 0.7487 & 2.68 \\
230 & 0.6985 & 2.60 \\
260 & 0.6625 & 2.64 \\
320 & 0.6047 & 2.62 \\
390 & 0.5468 & 2.58 \\
450 & 0.4929 & 2.62 \\
490 & 0.4508 & 2.71 \\
580 & 0.4060 & 2.59 \\
660 & 0.3499 & 2.65 \\
750 & 0.3021 & 2.66 \\
890 & 0.2508 & 2.59 \\
10,300 & 0.2005 & 2.60 \\
& & \\
\hline
\end{tabular}

$$
V=k c_{\mathrm{cat}}^{1 / 2} c_{\mathrm{AH}}^{1 / 2} c_{\mathrm{B}}
$$

Other imides (PI, GI) react with $\mathrm{EO}$ and $\mathrm{PO}$ according to the same rate law (Table 3).

\subsection{Reactivity of Monoimides and Oxiranes}

Electronic inductive effect is mostly responsible for reactivity of oxiranes as it was already discussed in [5]:

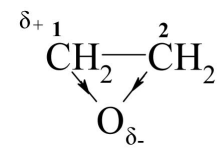<smiles>C[C@@H]1COO1</smiles> 
Table 3. Rate constants $k_{3 / 2} \cdot 10^{5}$ of the reactions of oxiranes with imides in presence of $\mathrm{NaOH}$ as catalyst.

\begin{tabular}{|c|c|c|c|c|c|c|c|}
\hline \multirow{2}{*}{ Imide } & \multirow{2}{*}{ Oxirane } & \multicolumn{6}{|c|}{ Rate constants $k_{3 / 2} \cdot 10^{5}\left[\mathrm{~mol}^{-1 / 2} \cdot \mathrm{s}^{-1} \cdot \mathrm{dm}^{3 / 2}\right]$ at temperature $[\mathrm{K}]$} \\
\hline & & 298 & 303 & 308 & 313 & 318 & 323 \\
\hline \multirow{2}{*}{ SI } & EO & $1.21 \pm 0.02$ & $1.73 \pm 0.06$ & $2.69 \pm 0.07$ & $4.37 \pm 0.20$ & & \\
\hline & $\mathrm{PO}$ & & & $1.28 \pm 0.05$ & $1.76 \pm 0.10$ & $3.10 \pm 0.18$ & $4.85 \pm 0.28$ \\
\hline \multirow{2}{*}{ PI } & $\mathrm{EO}$ & $1.25 \pm 0.03$ & $1.95 \pm 0.02$ & $3.17 \pm 0.17$ & $4.52 \pm 0.20$ & & \\
\hline & $\mathrm{PO}$ & & & $1.53 \pm 0.13$ & $2.18 \pm 0.12$ & $3.15 \pm 0.11$ & $4.53 \pm 0.35$ \\
\hline \multirow{2}{*}{ GI } & EO & $1.94 \pm 0.33$ & $3.09 \pm 0.36$ & $4.07 \pm 0.35$ & $6.17 \pm 0.22$ & & \\
\hline & $\mathrm{PO}$ & & & $1.77 \pm 0.22$ & $2.18 \pm 0.13$ & $3.88 \pm 0.30$ & $5.47 \pm 0.22$ \\
\hline
\end{tabular}

Higher reactivity of EO than PO was expected, because electrophilicity of C-1 in $\mathrm{PO}$ is weakened due to electrodonation from methyl group. Experimental rate constants for reactions of EO and PO with SI and PI are 2.1-2.6 times higher for EO than for PO (Table 3). The reactivity of SI and PS with oxiranes is almost the same, while GI is more reactive (Table 4). We tentatively attributed this to difficult stabilization of glutarimide anion due to its out-of-plane distortion in comparison with planar other imide anions. Determined rate constants of reactions between oxiranes and imides enabled us to establish the following order of reactivity for imides and oxiranes, which was the same as for analogous reactions catalyzed by triethylamine [5]:

$$
\mathrm{GI}>\mathrm{PI} \geq \mathrm{SI} \text { and } \mathrm{EO}>\mathrm{PO}
$$

Gibbs activation energy $\left(\Delta G^{\star}\right)$ for these reactions was determined in function of temperature. The plots $\Delta G^{ \pm}=f(T)$ are linear (Figure 3) which means that the same mechanism was ruling the kinetics within the studied temperature range. Averaged activation enthalpy, entropy and Gibbs energy, determined using Eyring formula, are collected in Table 5. The value of entropy changes suggests two-molecule intermediate state because dividing the value of $\Delta S^{\star}$ by $50 \mathrm{~J} / \mathrm{mol} \mathrm{K}$ the value of changes in entropy contributed to restriction of translation, rotation and oscillation of one mol of molecules involved in intermediate state [15] gives ca 2, which corroborate well with proposed further mechanism of reaction (vide infra; elementary reaction 14).

The intermediate state in case of reaction with GI is more restricted. This might be the largest limitation of rotational degrees of freedom at intermediate state of non-planar hexa-membered ring of GI. The relationship of changes in enthalpy vs. entropy of activation for all studied systems is shown in Figure 4. The relationship is isokinetic, which indicates that all the reaction within the series obey the same mechanism [15].

\subsection{Kinetic Evidences for Proposed Mechanism}

Based on experimentally derived kinetic law (10) for reaction of cyclic imides (AH) with oxiranes (B) in presence of sodium hydroxide $s$ catalyst (Cat) the following elementary reaction can be postulated: 


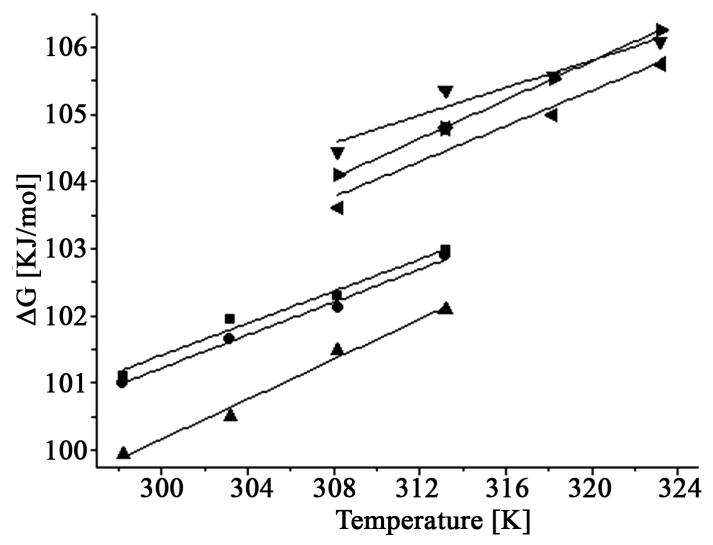

Figure 3. The changes of Gibbs energy of activation in function of temperature for the following reactions: $\mathrm{SI}+\mathrm{EO}(\boldsymbol{M} \mathrm{SI}+\mathrm{PO}(\boldsymbol{\nabla})$, $\mathrm{PI}+\mathrm{EO}(\boldsymbol{O}), \mathrm{PI}+\mathrm{PO}(\boldsymbol{\bullet}, \mathrm{GI}+\mathrm{EO}(\boldsymbol{\Delta}), \mathrm{GI}+\mathrm{PO}(\triangleleft)$.

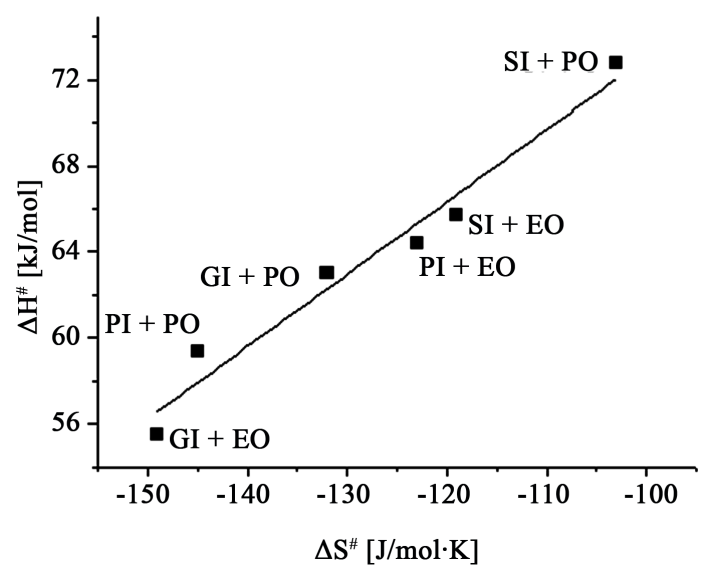

Figure 4. Isokinetic relationship for the reaction of monoimides with oxiranes.

Table 4. Relative reactivity of imides and oxiranes at $40^{\circ} \mathrm{C}$.

\begin{tabular}{ccc}
\hline Substrate & System & Relative reactivity \\
\hline SI & EO:PO & $1.00: 0.44$ \\
PI & EO:PO & $1.00: 0.48$ \\
GI & EO:PO & $1.00: 0.39$ \\
EO & SI:PI:GI & $1.00: 1.07: 1.47$ \\
PO & SI:PI:GI & $1.00: 1.10: 1.25$ \\
\hline
\end{tabular}

Table 5. Activation parameters for the reactions of imides with oxiranes.

\begin{tabular}{ccccccc}
\hline Imide & Oxirane & $\begin{array}{c}\text { Temperature } \\
\text { range }[\mathrm{K}]\end{array}$ & $\begin{array}{c}\Delta \mathrm{G}^{\#} \\
{[\mathrm{~kJ} / \mathrm{mol}]}\end{array}$ & $\begin{array}{c}\Delta \mathrm{H}^{\#} \\
{[\mathrm{~kJ} / \mathrm{mol}]}\end{array}$ & $\begin{array}{c}\Delta \mathrm{S}^{\#} \\
{[\mathrm{~J} / \mathrm{mol} \cdot \mathrm{K}]}\end{array}$ & $\begin{array}{c}\text { Correlation } \\
\text { coefficient }\end{array}$ \\
\hline \multirow{2}{*}{ SI } & EO & $298-313$ & $102.1 \pm 4.3$ & $65.7 \pm 3.9$ & $-119 \pm 13$ & 0.9670 \\
& PO & $308-323$ & $105.4 \pm 9.8$ & $72.8 \pm 5.9$ & $-103 \pm 9$ & 0.9095 \\
\multirow{2}{*}{ PI } & EO & $298-313$ & $101.9 \pm 8.8$ & $64.4 \pm 2.4$ & $-123 \pm 8$ & 0.9881 \\
& PO & $308-323$ & $105.2 \pm 0.7$ & $59.4 \pm 0.4$ & $-145 \pm 1$ & 0.9998 \\
\multirow{2}{*}{ GI } & EO & $298-313$ & $101.0 \pm 7.3$ & $55.5 \pm 3.6$ & $-149 \pm 12$ & 0.9815 \\
& PO & $308-323$ & $104.8 \pm 5.6$ & $63.0 \pm 5.1$ & $-132 \pm 10$ & 0.8945 \\
\hline
\end{tabular}


- dissociation of $\mathrm{NaOH}$ in DMSO:

$$
\begin{gathered}
\mathrm{NaOH} \underset{\mathrm{Na}}{\rightleftarrows} \mathrm{Na}^{+}+\mathrm{OH}^{-} \\
\mathrm{Cat} \underset{k_{-1}}{\stackrel{k_{1}}{\rightleftarrows}} \mathrm{at}^{+}+\mathrm{C}^{-}
\end{gathered}
$$

- formation of imide anions $\left(\mathrm{A}^{-}\right)$in reaction of hydroxyl anions $\left(\mathrm{C}^{-}\right)$from catalyst:

$$
\begin{aligned}
& \mathrm{R}_{-\mathrm{CO}^{\prime}}^{-\mathrm{CO}} \mathrm{NH}+\mathrm{OH}^{-} \rightleftharpoons \mathrm{R}_{-\mathrm{CO}^{\prime}}^{-\mathrm{NO}^{-}}+\mathrm{H}_{2} \mathrm{O} \\
& \mathrm{AH}+\mathrm{C}^{-} \underset{k_{-2}}{\stackrel{k_{2}}{\rightleftarrows}} \mathrm{A}^{-}+\mathrm{HC}
\end{aligned}
$$

- reaction of imide anion with oxirane with formation of alcoholate $\left(\mathrm{AB}^{-}\right)$:

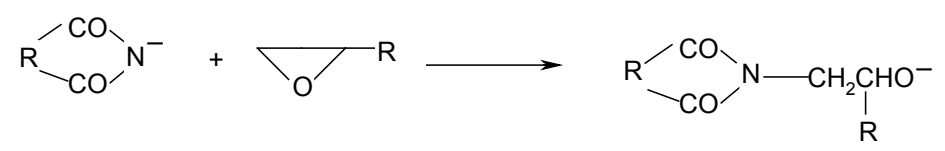

$$
\mathrm{A}^{-}+\mathrm{B} \stackrel{k_{3}}{\longrightarrow} \mathrm{AB}^{-}
$$

- neutralization of alcoholate with recovery of catalytic anion:

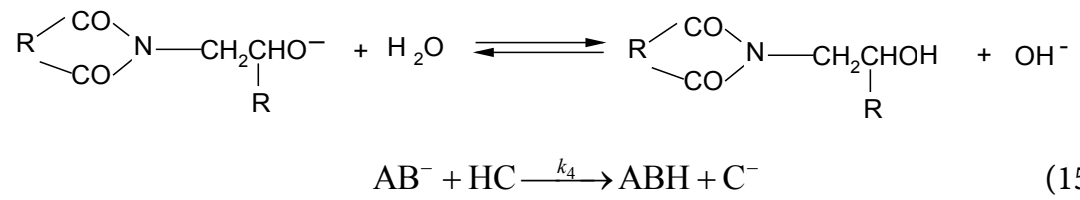

The acronyms under formula in Schemes $13-15$ will be then used in kinetic equations of elementary reactions.

I assume that:

1) Dissociation of $\mathrm{NaOH}$ is fast reaction (12);

2) Reaction of hydroxyl group with imide is also fast hydrogen cation transfer (13);

3) Rate limiting of the whole process is attack of imide anion on oxirane (14);

4) Neutralization of alcoholate is also fast reaction (15), the oxirane consumption is equal to imide anion consumption, i.e.:

$$
V_{\text {gen }}=-\frac{\mathrm{d} c_{\mathrm{B}}}{\mathrm{d} t}=\frac{\mathrm{d} c_{\mathrm{A}^{-}}}{\mathrm{d} t}=k_{3} c_{\mathrm{A}^{-}} c_{\mathrm{B}}
$$

The concentration of $c_{\mathrm{A}^{-}}$can be found from stationary state condition [15]:

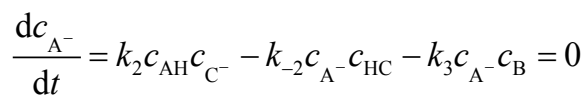

Because

$$
c_{\mathrm{A}^{-}}=c_{\mathrm{HC}}
$$

then

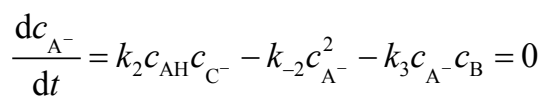

and further 


$$
c_{\mathrm{A}^{-}}=\frac{-k_{3} c_{\mathrm{B}}+\sqrt{k_{3}^{2} c_{\mathrm{B}}^{2}+4 k_{-2} k_{2} c_{\mathrm{AH}} c_{\mathrm{C}^{-}}}}{2 k_{-2}}
$$

From 2 and 3 it results in: $k_{3} c_{\mathrm{B}} \ll$ and

$$
k_{3} c_{\mathrm{B}} \ll 4 k_{-2} k_{2} c_{\mathrm{AH}} c_{\mathrm{C}^{-}}
$$

This enables to simplify relationship (20) to:

$$
c_{\mathrm{A}^{-}}=\frac{\sqrt{4 k_{-2} k_{2} c_{\mathrm{AH} c_{\mathrm{C}^{-}}}}}{2 k_{-2}}=\sqrt{K_{2} c_{\mathrm{AH}} c_{\mathrm{C}^{-}}}
$$

where:

$$
K_{2}=\frac{k_{2}}{k_{-2}}
$$

Introducing (22) to Equation (16) one can obtain:

$$
V_{\text {gen }}=k_{3} \sqrt{K_{2}} c_{\mathrm{AH}}^{1 / 2} c_{\mathrm{C}^{-}}^{1 / 2} c_{\mathrm{B}}
$$

Assuming that:

$$
c_{\mathrm{C}^{-}}=c_{\mathrm{cat}}
$$

and substituting (25) to (24) gives:

$$
V_{\text {gen }}=k_{3} \sqrt{K_{2}} c_{\mathrm{cat}}^{1 / 2} c_{\mathrm{AH}}^{1 / 2} c_{\mathrm{B}}
$$

The Equation (26) can be simplified into:

$$
V_{\text {gen }}=k c_{\text {cat }}^{1 / 2} c_{\mathrm{AH}}^{1 / 2} c_{\mathrm{B}}
$$

where:

$$
k=k_{3} \sqrt{K_{2}}
$$

Derived Equation (27) is in accordance with experimental one (10) indicating that propsed mechanism is kinetically proper. The compatibility of derived and experimental equations occurs provided a dissociation of $\mathrm{NaOH}$ in DMSO is irreversible, i.e. $k_{-1}=0$. If only partial dissociation of $\mathrm{NaOH}$ is taken into accout, the following relationship can be derived:

$$
V_{\text {gen }}=k c_{\text {cat }}^{1 / 4} c_{\mathrm{AH}}^{1 / 2} c_{\mathrm{B}}
$$

which is not in accordance with the experimental one.

\subsection{Non-Kinetic Evidences on Proposed Mechanism}

In order to verify the proposed mechanism and the adopted assumption we have experimentally studied:

- the equilibrium between imide and sodium hydroxide in DMSO (13);

- the consecutive products in studied systems.

The equilibrium between reagents in imide-sodium hydroxide system was studied by straightforward measurements of conductance of 1-molar solution of SI and PI imides in DMSO, separately for $0.05 \mathrm{~mol} / \mathrm{dm}^{3} \mathrm{NaOH}$ solution in DMSO. The solubility of $\mathrm{NaOH}$ in neat DMSO limited using concentration of 
$\mathrm{NaOH}$ for conductivity measurement in contrary to its solubility in DMSO in presence of imides, with which it reacts (13). In kinetic experiments the $\mathrm{NaOH}$ solubility was as high as $0.2 \mathrm{~mol} / \mathrm{dm}^{3}$. Then conductivity measurement was performed for mixture of $1.00 \mathrm{M}$ imide and $0.05 \mathrm{M}$ sodium hydroxide in DMSO (Table 6). The conductivity of $\mathrm{NaOH}$ in DMSO is much higher than conductance of nest DMSO, while the conductivity of imide solution in DMSO is only slightly higher than that of the solvent. Finally, the conductivity of mixture of imide and $\mathrm{NaOH}$ solution is considerably higher than additive conductance of component solutions. This may indicate a partial dissociation of sodium imidates in DMSO in presence of water formed upon reaction (13). Further evidences on equilibrium (13) were provided by H-NMR spectroscopy (Figure 5). The imide proton resonance of succinimide at $11 \mathrm{ppm}$ (Figure 5(a)) disappeared upon addition of sodium hydroxide into the solution of SI in DMSO- $\mathrm{d}_{6}$ (Figure 5(b)). Also the residual water resonance at $3.3 \mathrm{ppm}$ in the spectrum of SI shifted downfield to $4.2 \mathrm{ppm}$ and its intensity increased considerably due to water released in reaction (13). At the same time methylene proton resonance (2.5 ppm) was shifted up field (up to $2.2 \mathrm{ppm}$ ) as could be expected for succinimidate anion. Similar behavior was observed for $\mathrm{PI}-\mathrm{NaOH}$ solution in DMSO- $\mathrm{d}_{6}$.

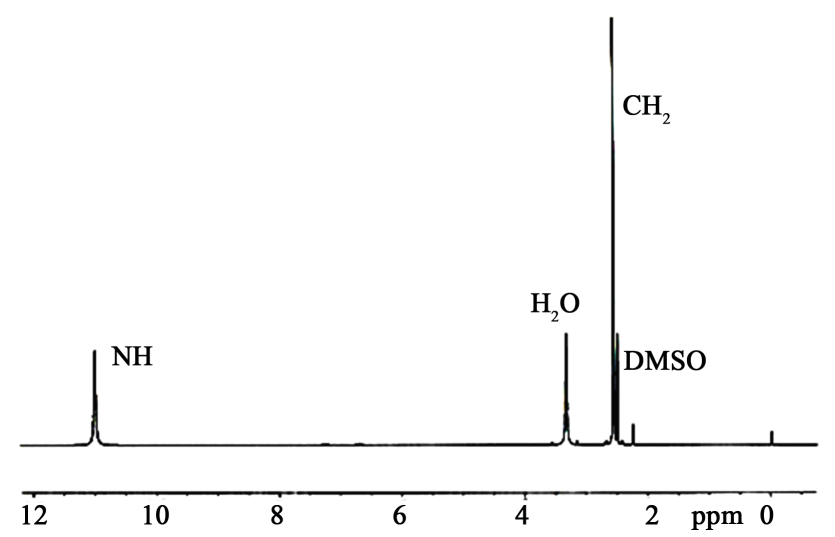

(a)

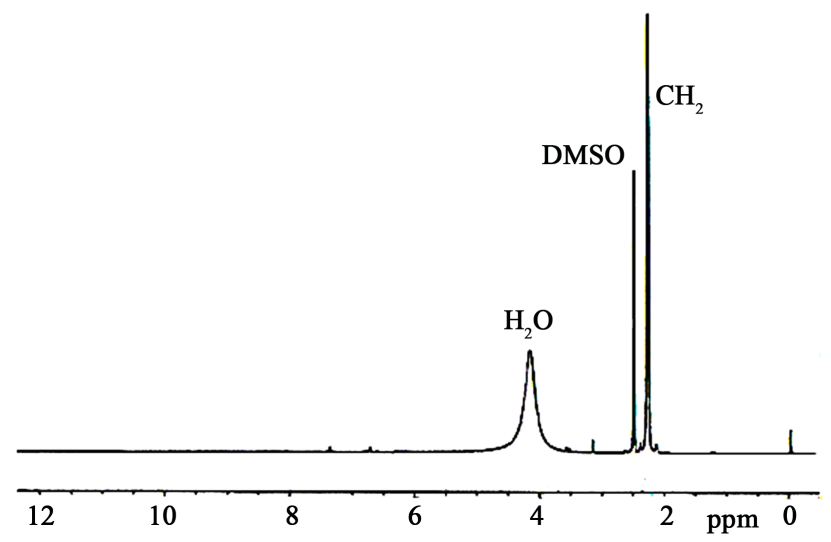

(b)

Figure 5. H-NMR spectrum of SI (a) and mixture of SI with $\mathrm{NaOH}$ (b). 
Table 6. Conductivity $[\mu \mathrm{S} / \mathrm{cm}]$ of $1 \mathrm{M}$ solutions of imides and $0.05 \mathrm{M} \mathrm{NaOH}$ in DMSO and of their mixtures.

\begin{tabular}{ccccccccc}
\hline \multirow{2}{*}{ DMSO } & \multirow{2}{*}{$\mathrm{NaOH}$} & \multirow{2}{*}{ SI } & \multirow{2}{*}{ PI } & \multicolumn{2}{c}{$\mathrm{SI}-\mathrm{NaOH}$} & \multicolumn{2}{c}{$\mathrm{PI}-\mathrm{NaOH}$} \\
\cline { 6 - 9 } & & & & & Additive & Experim & Additive & Experim \\
\hline 5.0 & 368 & 21 & 45 & 389 & 506 & 413 & 533 \\
\hline
\end{tabular}

We have analyzed the products of reaction mixtures used for kinetic measurements by chromatography. We have found that post-reaction mixtures contained $98 \%$ - 99\% pure N-(hydroxyalkyl)imides. No unreacted imides were detected in contrary to earlier analogous mixtures in presence of triethylamine catalyst [5]. After recrystallization of products the IR spectra and melting temperatures were compared with the products isolated earlier [4] confirming the identity of products isolated hereof.

Heating of solution of $\mathrm{N}$-(2-hydroxyalkyl)imide in DMSO in presence of oxirane and $\mathrm{NaOH}$ catalyst at $40^{\circ} \mathrm{C}$ for 48 hours did not result in further contraction of volume of the mixture, again suggesting that no further reaction of $\mathrm{N}$-(2-hydroxyalkyl)imide with oxirane took place. Thus the reaction system applied here can be exploited as synthetic route to obtain N-(2-hydroxyalkyl)imides with high yield not only for monoimides but also for multifunctional imides of mentioned earlier isocyanuric, barbituric, and uric acids.

\section{Summary and Conclusions}

1) Monocyclic imides react with oxiranes in presence of sodium hydroxide to form corresponding $\mathrm{N}$-(2-hydroxyalkyl)imides. No consecutive reactions of $\mathrm{N}$-(2-hydroxyalkyl)imides with oxiranes take place in contrary to the analogous system with triethylamine.

2) Kinetics of reaction between cyclic imides and oxiranes can be described by following rate law:

$$
V_{\text {gen }}=k c_{\text {cat }}^{1 / 2} c_{\mathrm{AH}}^{1 / 2} c_{\mathrm{B}}
$$

where $c_{\text {cat }}, c_{\mathrm{AH}}$, and $c_{\mathrm{B}}$ are concentration of catalyst, imide, and oxirane, respectively.

3) The reaction mechanism was proposed based upon experimentally determined rate law for the reaction of cyclic monoimides and oxiranes as well as analytical and instrumental analysis of products. All the studied reactions obey the same mechanism as can be concluded from isokinetic relationship of studied systems.

4) The elementary reaction between oxirane and imide anion is rate determining step. The imide anion is formed by hydrogen cation transfer into catalytic hydroxide anion from dissociated $\mathrm{NaOH}$.

\section{Conflicts of Interest}

The authors declare no conflicts of interest regarding the publication of this paper. 


\section{References}

[1] Steele, R., Katzakian, A., Scigliano, J. and Hamel, E. (1976) Imide Oxirane Reactions. US Patent No. 3962182.

[2] Schoenfeldt, N. (1976) Grenzflaechenactive Aethylenoxid-Addukte. Wissenschaftliche Verlagsgesellschaft MBH, Stuttgart.

[3] Tawney, P. (1950) N-Methylol Maleimide. US Patent No. 2526517.

[4] Weitzel, G., Schneider, F., Fretzdorf, A., Seynsche, K. and Finger, H. (1963) Futher Tumor Inhibiting Compounds. I. Cytostatic Effects of $N$ - and $S$-Hydroxy-Methyl Compounds. Zeitung Physiologische Chemie, 334, 1-25. https://doi.org/10.1515/bchm2.1963.334.1.1

[5] Lubczak, J. (2012) Hydroxyalkylation of Cyclic Imides with Oxiranes Part I. Kinetics of Reaction in Presence of Triethylamine Catalyst. Open Journal of Physical Chemistry, 2, 88-96. https://doi.org/10.4236/ojpc.2012.22012

[6] Lubczak, J. (2012) Hydroxyalkylation of Cyclic Imides with Oxiranes Part II. The Mechanism of Reaction in Presence of Triethylamine. Open Journal of Physical Chemistry, 2, 97-102. https://doi.org/10.4236/ojpc.2012.22013

[7] Kucharski, S. (1971) Nonionic Surfactants. I. Preparation of Poly(Oxyethylene) Alcohols. Wiadomości Chemiczne, 25, 579-594.

[8] Lebedev, N. and Shvets, V. (1968) Mechanism of Ethylene Oxide Reactions with Phenols. Kinetika i Kataliz, 9, 504-510.

[9] Shvets, V. and Lykov, I.Y. (1971) Kinetics and Mechanism of the Reaction of Ethylene Oxide with $n$-Decyl Mercaptan during Basic Catalysis. Kinetika i Kataliz, 12, 347-355.

[10] Shvets, V., Romashkin, A. and Yudina, V. (1973) Kinetics and Mechanism of the Reaction of Ethylene Oxide with Terephthalic Acid during Catalysis by Tetraal-Kylammonium Halides. Kinetika i Kataliz, 14, 928-932.

[11] Weindenbacher, A., Serban, S. and Weindenbacher, E. (1964) Kinetics of Ethoxylation Reactions in Series of Primary Aliphatic-Amines. Revista de Chimie, 29, 204-209.

[12] Knaggs, E. (1964) Alkanoloamides in Soft Detergents. Soap Chemical Specialties, 40, 79-83.

[13] Grossmann, H. (1972) Die Beeinflussung der Reaktion bei der Oxaethylierung von Fettsaeuremonoaethanol-Amiden. Fette, Seifen, Anstrichmittel, 74, 58-63. https://doi.org/10.1002/lipi.19720740111

[14] Lubczak, J. (2011) Polyhydroxyalkyl Derivatives and Polyetherols Obtained from Azacyclic Compounds. Part I. Reactions with Oxiranes. Polimery, 56, 360-368.

[15] Schwetlick, K. (1971) Kinetische Methoden zur Untersuchung von Reactionsmechanismen. VEB, Deutscher Verlag der Wissenschaften, Berlin. 